\title{
Manicômio Adauto Botelho: A Psiquiatria em Goiás
}

Manicômio Adauto Botelho: The Psychiatry in Goiás

\section{Éder Mendes de Paula ${ }^{1}$}

\section{Resumo}

O presente artigo pretende analisar como o ideal de modernidade foi aplicado no estado de Goiás, utilizando-se da relação entre os discursos médico-psiquiátrico e o político. Assim, passando pela construção de Goiânia até o Manicômio Adauto Botelho, intenciona-se construir uma análise sobre o período e como a representação do ser moderno foi conduzida em Goiás. O período abordado corresponde ao momento em que Getúlio Vargas chega ao poder, com o discurso alicerçado na ideia de deixar para trás os tempos do coronelismo, inaugura-se uma perspectiva de progresso que reverbera por vários governos estaduais no Brasil. Foram utilizados documentos como a Revista Goiana de Medicina, a compilação dos Arquivos de Saúde Pública entre 1951-1954 e avulsos arquivados no Arquivo Histórico Estadual. A análise do discurso foi o ponto fulcral para a interpretação e relação entre as fontes, buscando nas entrelinhas e nos intertextos a lógica sobre saúde, política e poder em Goiás.

Palavras-Chave: Saúde; Política; Modernidade.

\begin{abstract}
This article aims to analyze how the ideal of modernity was applied in the state of Goiás, using the relation between medical-psychiatric and political discourses. Thus, passing through the construction of Goiânia to the Manicômio Adauto Botelho intends to construct an analysis about the period and how the representation of the modern being was conducted in Goiás. The period approached corresponds to the moment in which Getúlio Vargas comes to power, with the discourse based on the idea of leaving
\end{abstract}

\footnotetext{
${ }^{1}$ Doutor pela Universidade Federal de Goiás. E-mail falecomoprofessoreder@gmail.com Recebido em 13 de agosto de 2018. Aprovado em 26 de agosto de 2019.
} 
behind the times of coronelismo, a perspective of progress that reverberates for several state governments in Brazil is inaugurated. Documents such as the Goiana Journal of Medicine, the compilation of the Public Health Archives between 1951-1954 and individual files filed in the State Historical Archives were used. Discourse analysis was the focal point for interpretation and relationship between sources, searching the lines between lines and intertexts for the logic of health, politics and power in Goiás.

Keywords: Health; Politics; Modernity.

\section{Introdução}

Para o estado de Goiás, no contexto em que a chamada civilização do litoral construiu o seu par opositor no interior do país, ou seja, para estabelecer um status de civilizado, era necessária a dicotomia que atribuísse sentido aos discursos construídos. Este espaço, que não é apenas geográfico, mas também narrativo, desenvolveu uma cultura própria mediante essas relações de poder entre o discurso do colonizador e o do colonizado.

Nesse sentido, é possível perceber relações que se configuram de maneiras particulares, como o fato de lidar com o louco e a loucura, constituindo traços de pessoalidade entre os tidos como anormais e a comunidade em seu entorno. No entanto, é preciso salientar que os projetos de modernização pensados e implementados a partir da era Vargas trouxeram uma nova configuração ao chamado sertão.

A sua cura, já que o mesmo era representado como um espaço doente e não civilizado, viria não através de uma medicalização social em que a psiquiatria teria um papel preponderante. $\mathrm{O}$ saber médico psiquiátrico, ao lidar diretamente com o comportamento dos indivíduos, auxiliaria a transformação do comportamento desses indivíduos para alcançar a concretização dos projetos políticos.

É nesse contexto que se situa esta análise, tomando como ponto de partida os discursos de mudança da capital e o papel da psiquiatria no ideal de modernização do estado de Goiás. Por meio da idealização e construção do Manicômio Adauto Botelho 
se intenta relacionar as nuances de entrelaçamento dos discursos político e psiquiátrico para a normatização e padronização da população goiana.

\title{
I- Psiquiatria: Construção do Louco
}

No mês de janeiro do ano de 1890, estava descrito no Relatório da Inspetoria de Higiene Pública do Estado de Goiás o seguinte dizer a respeito dos alienados:

\begin{abstract}
Infelizes porque a caridade pública parece esquecê-los e negar-se a estenderlhes a sua benfazeja mão, infelizes porque o governo até agora tem se mostrado surdo aos seus gemidos e quando alguma providência se toma é apenas para retirá-los da sociedade, quais animais hidrófobos [sic] e senão curá-los, mitigar os seus cruéis sofrimentos, prestando de acordo com a civilização real, serviço à humanidade e à ciência. (Relatório da Inspetoria de Higiene Pública do Estado de Goyaz, jan. 1890 apud SALLES, 1999, p. 99).
\end{abstract}

Eram homens e mulheres condenados à própria sorte por terem sido acometidos de doença mental, tipos que vagavam, no final do século XIX, pelas ruas da antiga capital da Província de Goiás, sem que houvesse um olhar particular para o mal que os afligia. Aqui, o Hospital de Caridade São Pedro de Alcântara funciona como um depósito de todos os tipos de doentes, sem atendimento específico no caso dos que sofriam de males mentais, construindo, assim, uma situação de abandono.

Esse ato de amontoar pessoas, mesmo que o Hospital não fosse destinado a receber esses doentes, parecia ser visto como a grande caridade. Um serviço à humanidade no sentido de limpeza não só das ruas, mas no de evitar-se a agitação. Não se vê o aval da psiquiatria em si, mas a medicina mostra seu poder de intervenção e o poder que lhe está atribuído. A historiadora Magali Engel (2005), em seu artigo "Um palácio para guardar doidos”, pesquisa como o Hospício Pedro II, inaugurado no Rio de Janeiro em 1852, funcionava como um espaço de amontoar pessoas, realizando uma espécie de higienização da cidade. Esse poder funciona como um direito sobre o confinamento. Direito que se transpõe e se legitima nas próprias pesquisas científicas.

O relatório nos esclarece a situação destes que não eram, até então em Goiás, contemplados com uma especialidade médica. Estes que eram confinados no Hospital de Caridade, o eram devido ao comportamento fora da norma. Estes eram chamados, muitas vezes, de agitadores, ou portadores de vícios, como o alcoolismo, que eram 
recolhidos exatamente porque suas atitudes não eram condizentes com o "normal". Tais indivíduos tornavam-se incômodos, o que levava à reclusão, considerada um serviço à sociedade "normal".

O esquecimento referido no documento supramencionado é causado pelo ato de ignorar esses "tipos urbanos". Os mesmos têm sua palavra invalidada pelo seu comportamento, dessa forma são lançados ao mar aberto. A própria preocupação presente no relatório não é com o seu silenciamento, mas com as pessoas sãs que, numa atitude caridosa, deveriam prestar socorro, sem que o seu discurso fosse necessariamente validado. Esse ato de reclusão visava à salvação da alma dos chamados doentes mentais que, naquele contexto, viviam em uma sociedade católica que lhes negava auxílio.

Havia, da mesma forma, aqueles que não eram recolhidos ao Hospital, que se tornavam parte integrante da paisagem local, pois,

devido à perpétua escassez de água potável, com que a população da Capital se vê a braços o ano inteiro, principalmente nos meses de seca, há aqui uma verdadeira legião de carregadores e carregadoras, em que predominam os débeis mentais - ocupada na baldeação de água para as habitações (PALACIN, 1976, p. 37).

Aos que podiam, de alguma forma, prestar um serviço público e que não representavam uma ameaça à ordem estabelecida, ficava o direito de ir e vir, mas nem por isso é dada uma importância à humanidade. O que eram ou o que pensavam, não fazia diferença àqueles que faziam uso de sua força para determinados afazeres. Eram considerados bobos demais para perceberem a realidade e, nesse sentido, tornavam-se prestativos, seus serviços não eram remunerados, realizavam a baldeação da água sem nada em troca, o que funcionava como uma forma de se verem inseridos em uma normalidade que, de fato, não lhes pertencia. Esse distanciamento era ocasionado de acordo com as fronteiras demarcadas pelo estabelecimento de padrões comportamentais.

Até a construção do Hospital Psiquiátrico Prof. Adauto Botelho, em Goiânia, a categoria "louco" não fazia parte efetiva da realidade do estado, não havia local de legitimação do discurso excludente. O Hospital Psiquiátrico Adauto Botelho foi inaugurado no ano de 1954, na então nova capital do estado de Goiás. Seu projeto foi 
idealizado e realizado pelo Serviço Nacional de Doenças Mentais, dirigido pelo médico Adauto Botelho durante o governo Vargas, em que um total de 8 hospitais foram construídos em diferentes regiões do Brasil. Sendo assim, inexistiam determinados comportamentos regidos por normas de um saber científico que estabelecesse padrões. Sem os espaços de emissão e legitimação do discurso excludente/enclausurador, não há categorização de louco e, consequentemente, a produção da loucura institucionalizada.

A exclusão médica praticada a partir da criação dos hospitais e dos laudos médicos complementa àquela realizada a partir do estigma de "tipos urbanos". Afinal, mesmo que estivessem fazendo parte do convívio social, o ato de servir para afazeres, como carregar a água para os moradores da cidade, como visto na citação anterior, não alterava sua condição, mantendo-os em subalternidade. No entanto, alguns conheciam os nomes, outros os apelidos, mas cada qual, dentro de sua particularidade, não era confinado em um mesmo patamar, uma única categoria.

A partir da construção de Goiânia, que se inicia com o lançamento da pedra fundamental em 1933 e seu batismo cultural em 1942, isso é sentido com mais intensidade, pois, na medida em que a cidade cresce, esses personagens parecem deixar de existir, mas, na verdade, eles se transmutam, não por si, mas pelo que dizem deles e de seus comportamentos.

\footnotetext{
Vão se acabando os nossos "tipos de rua". Não se veem hoje como outrora os "Funga-Funga", os "Zé Mangarito", os "Antonio Louco" e outros, no espalhafato que armavam em plena via pública, cada qual na sua especialidade, acossados pela garotada, e que fazia muita gente vir à janela Despareceram. (Revista Oeste, julho de 1942).
}

Encontra-se nessa edição da Revista Oeste um saudosismo em relação aos tipos urbanos que faziam parte da cidade, do convívio direto de seus habitantes, ainda não categorizados, ainda não confinados. Esse desaparecimento não deve ser visto como um sumiço, um deixar de existir, mas uma ausência ocasionada pela institucionalização.

No ano de 1942, não se tem ainda a inauguração do Hospital Psiquiátrico Adauto Botelho, mas, desde antes, já existia a preocupação em se construir um local para os não adaptados sociais,

apesar do elevado porte do empreendimento da Santa Casa, a Conferência começa a atuar na campanha pela instalação do sanatório para alienados. Foi 
proposta a confecção de selos de \$100 e \$200, para serem vendidos formando um fundo para as obras" (DOLES apud FREITAS, 1999, p. 308).

Goiânia, como a nova capital, erguia-se para sustentar um número maior de habitantes, dessa maneira, as relações sociais existentes são transformadas. Ou seja, determinados indivíduos não figuram mais no íntimo da sociedade, mas são relegados a um esquecimento a partir de uma categorização. Antes sua fala poderia ser desprezada, agora, além dela, sua própria imagem é retirada e colocada por trás de altos muros que impedem, a qualquer um, a sua visualização. Nesse ínterim, são retirados da História os "anormais", tornando-os parte de um vazio quase que eterno, representado apenas por tijolos empilhados, uma fortaleza que protege os de fora.

O projeto de Goiânia teve como porte arquitetônico o Art Déco e priorizou a centralização do poder do estado em torno de uma praça, denominada praça cívica, de onde partiam/partem as principais avenidas da cidade. Seu projeto contemplou bairros ligados a esse tronco principal, Avenida Goiás, Avenida Araguaia, Avenida Tocantins, mais distante ficava o setor Macambira, hoje Pedro Ludovico.

Esse espaço deveria contemplar um novo projeto para o estado de Goiás, um projeto de modernização que deveria estar representado na arquitetura e no comportamento dos moradores. Daí a importância da construção do sanatório, principalmente, da sua localização ser fora desse tronco principal, deixando evidente a exclusão dos comportamentos tidos como não aceitos, inadequados para a sociedade que se cogitava naquele momento.

Essa ênfase na construção de um hospital para alienados em Goiás justifica-se por a psiquiatria ser parte de um saber médico que atua com eficácia na vida dos indivíduos. Em Goiás, há a particularidade de que o então governador/interventor Pedro Ludovico Teixeira, nomeado em 1930 por Vargas, era médico e é através de seu discurso de que a então capital Vila Boa era um espaço doente, propício à proliferação de miasmas, que se dá a elaboração do projeto e a construção da nova capital, Goiânia. Nesse sentido, o saber médico ganha um espaço de grande atuação em Goiás e de legitimação por parte da população, que se configura na consolidação da Associação Médica de Goiás e sua publicação "Arquivos de Saúde Pública”, que se dará nas décadas seguintes, até a construção da Faculdade de Medicina. 
Essa atuação do saber médico não diz respeito apenas a cuidados com higiene, como o que comer, o que vestir, onde morar e como morar. Mas como falar, o que falar, o que pensar, como andar, quando andar, como se portar com os olhos, os gestos. Em suma, uma economia do corpo que não está sustentada apenas na mente, nos delírios que são impalpáveis, mas na querência de localizá-los através do comportamento expresso pelo corpo. Assim, sua consolidação permite uma maior utilização desse saber, desse local do inquestionável, atuar com mais voracidade sobre o comportamento humano.

O exemplo disso foi o primeiro hospício a ser inaugurado no Brasil, o Pedro II, no ano de 1852, no Rio de Janeiro, que

\begin{abstract}
passou a ser habitado por homens e mulheres livres ou libertos, muito pobres ou miseráveis, que andavam pelas ruas da cidade assumindo comportamentos diferentes dos considerados "normais". A grande maioria da população do hospício era internada pelas mãos da polícia na categoria de indigentes. Entre estes figuravam alguns poucos escravos que pertenciam a senhores pobres. [...] Os diretores do serviço clínico reclamavam das péssimas condições da instituição e da sua ineficácia para aprisionar, tratar e curar a loucura. As queixas ganharam um tom mais eficaz nos anos de 1880, através da voz do Dr. Teixeira Brandão, considerado por muitos o pai da psiquiatria brasileira. [...] Com a Proclamação da República, muitas das reivindicações do eminente psiquiatra foram atendidas. Uma das primeiras medidas do novo regime foi separar o hospício da Santa Casa, passando a designá-lo Hospício Nacional de Alienados (HNA). [...] Sem dúvida, a instituição republicana era muito eficiente no exercício do controle social. Os indivíduos cujas ações ou pensamentos fossem considerados de alguma forma perigosos à ordem estabelecida constituíam o principal alvo das internações. Exemplo expressivo nesse sentido foi o de João Cândido, um dos principais líderes da Revolta da Chibata (1910), que depois de preso e torturado acabou internado no HNA (ENGEL, 2005, p. 35).
\end{abstract}

Desde o século XIX, o Estado utiliza o discurso médico psiquiátrico como forma de controle, como forma de estabelecer comportamentos tidos como aceitos. Nesse contexto, era auxiliada ou auxiliava o aparelho político em que a própria polícia encaminhava determinados pacientes. No caso citado, de João Cândido, o mesmo é considerado louco devido a suas ideias que não condiziam com as intenções políticas da época. Tal evidência não significa que aquele padrão foi aplicado ao longo dos anos, pois, segundo Ana Bock, cada cultura constrói suas "próprias zonas patológicas" (BOCK, 2003, p. 30).

Nesse sentido, as fronteiras entre o normal e o patológico não se tornam apenas tênues, elas tornam-se múltiplas, mutáveis ao longo dos processos sociais. Variam de 
acordo com a própria sociedade, transforma a economia do corpo de acordo com as mudanças que ocorrem e os interesses dos produtores dos discursos. Cabia ao médico o papel de retirar dos tidos como "anormais" o direito de ser o que eram, a partir do momento em que esses indivíduos se tornavam pacientes, seja pelas mãos da família ou mesmo do Estado.

É interessante observar que essas relações de poder e essas fronteiras já existiam, porém, não institucionalizadas. As diferenças entre os tipos urbanos são demarcadas pelo direito de dizer, por mais que não houvesse o confinamento. A massificação de todos eles em uma única categoria de exclusão os tornou invisíveis em suas particularidades. Isso cunhou exatamente a distância entre a relevância e a irrelevância das palavras de cada par opositor.

A grande questão que envolve o louco e seu discurso é o fato de que a própria negação de sua condição passa a ser utilizada como sintoma. Os dizeres sobre o que é normalidade e anormalidade são colocados, então, entre duas autoridades que, de certa maneira, se completam: a autoridade médica e a autoridade civil. Essa relação está presente desde a consolidação da psiquiatria no Brasil, fato que ocorre já no século XX.

Diante de um tratamento que era de responsabilidade das Santas Casas de Misericórdia, os médicos começam uma busca por consolidar seus conhecimentos. Encontrar uma linha de atuação e exercer a psiquiatria no Brasil de uma maneira científica e não vinculada à religiosidade, com características próprias.

Apesar do pensamento científico, a psiquiatria funcionava de acordo como as necessidades políticas do momento histórico. Haja vista que, no início do século XX, encontram-se denúncias acerca do HNA (Hospital Nacional de Alienados) - antigo Hospício Pedro II do período imperial - em que o mesmo parece funcionar como um depósito de pessoas pobres. Um confinamento aos comportamentos não aceitos pela sociedade vigente, sem vistas a tratamentos mais sistematizados.

Sua institucionalização ganha corpo a partir do primeiro terço do século $\mathrm{XX}$ quando é criada a LBHM (Liga Brasileira de Higiene Mental). Nesse período, 
a psiquiatria [...] era produto do atraso histórico da Psiquiatria no Brasil. Até Juliano Moreira ${ }^{2}$, a Psiquiatria ${ }^{3}$ tinha-se limitado a reproduzir o discurso teórico da Psiquiatria francesa e a seguir a prática ditada pelo pessoal leigo ou religioso, encarregado da administração dos hospitais. Juliano Moreira e seus discípulos tentaram transformar esta situação, inaugurando uma Psiquiatria cujos fundamentos teóricos, práticos e institucionais constituíram um sistema psiquiátrico coerente. (COSTA, 1980, p. 23)

A Liga Brasileira de Higiene Mental é inaugurada no Brasil por Riedel, no ano de 1923. Durante os seus dois primeiros anos de atuação, a ideia era de que se buscassem estudos que visassem à melhoria no atendimento ao doente, juntamente com o aperfeiçoamento de técnicas. A partir de 1926, os médicos que compõem a Liga passam a dar um novo olhar para a instituição. Começam a preocupar-se não apenas a aperfeiçoar as técnicas de tratamento, mas também a buscar uma prevenção aos males mentais. Dessa forma, o interesse se dirige ao indivíduo sadio e não ao doente.

Neste momento, a psiquiatria volta-se para o social, diante da possibilidade de se realizar uma profilaxia. Este saber começa a se interessar pelo comportamento dos indivíduos normais, ou ainda, traçar um comportamento ideal.

\footnotetext{
2 Juliano Moreira (1873-1933), baiano de Salvador, é frequentemente designado como fundador da disciplina psiquiátrica no Brasil. Sua biografia justifica tal eleição: mestiço (mulato), de família pobre, extremamente precoce, ingressou na Faculdade de Medicina da Bahia aos 13 anos, graduando-se aos 18 anos (1891), com a tese "Sífilis maligna precoce". Cinco anos depois, era professor substituto da seção de doenças nervosas e mentais da mesma escola. De 1895 a 1902, frequentou cursos sobre doenças mentais e visitou muitos asilos na Europa (Alemanha, Inglaterra, França, Itália e Escócia). De 1903 a 1930, no Rio de Janeiro, dirigiu o Hospício Nacional de Alienados. Neste, embora não fosse professor da Faculdade de Medicina do Rio, recebia internos para o ensino de psiquiatria. Aglutinou ao seu redor médicos que viriam a ser, eles também, organizadores ou fundadores na medicina brasileira, de diversas especialidades: neurologia, psiquiatria, clínica médica, patologia clínica, anatomia patológica, pediatria e medicina legal, tais como Afrânio Peixoto, Antonio Austragésilo, Franco da Rocha, Ulisses Viana, Henrique Roxo, Fernandes Figueira, Miguel Pereira, Gustavo Riedel e Heitor Carrilho, entre outros. Um aspecto marcante na obra de Juliano Moreira foi sua explícita discordância quanto à atribuição da degeneração do povo brasileiro à mestiçagem, especialmente a uma suposta contribuição negativa dos negros na miscigenação. A posição de Moreira era minoritária entre os médicos, na primeira década do século XX, época em que ele mais diretamente se referiu a esta divergência, polemizando com o médico maranhense Raimundo Nina Rodrigues (1862-1906). Também desafiava outro pressuposto comum à época, de que existiriam doenças mentais próprias dos climas tropicais. (ODA, p. 04).
}

\footnotetext{
${ }^{3}$ Surgiu, no século XVIII, Phillippe Pinel, considerado o pai da psiquiatria, que teve o mérito de libertar os doentes mentais das correntes. Os asilos foram substituídos, então, pelos manicômios, estes somente destinados aos doentes mentais. Desenvolveram-se com isso várias experiências e formas de tratamento nos hospitais La Bicêtre e Salpêtrière que se difundiram da França para o resto da Europa. O tratamento no manicômio, de acordo com Pinel deveria ser de reeducação do alienado, implicando respeito às normas e desencorajamento das condutas inconvenientes. "A função disciplinadora do manicômio e do médico deve ser exercida como um perfeito equilíbrio entre firmeza e gentileza. Mais ainda, a permanência demorada do médico em contato com os doentes melhora seu conhecimento sobre os sintomas e sobre a evolução da loucura", afirmava Pinel. Porém com o passar do tempo houve uma leitura modificada do tratamento moral de Pinel, sem os cuidados originais do método. As ideias corretivas para o comportamento dos hábitos dos doentes passaram a ser recursos de imposição da ordem e da disciplina institucional, recursos estes que visavam naquele momento ao bem da instituição. Tudo era justificado para submeter o doente mental. No início do século XIX o tratamento do doente era uma releitura distorcida do tratamento moral de Pinel e utilizava medidas físicas e higiênicas como duchas, banhos frios, chicotadas, máquinas giratórias e sangrias. Aos poucos, o que era considerado como uma doença moral passou também a ter uma concepção orgânica, de acordo com o pensamento de vários discípulos de Pinel. (LOPES, p. 01).
} 
Os psiquiatras, seguindo a nova concepção de prevenção, deslocam-se, pouco a pouco, da prática tradicional e penetram no domínio cultural, até então situado fora dos domínios da Psiquiatria. De 1928 a 1934, acentua-se este distanciamento da teoria e da prática psiquiátrica correntes. Os psiquiatras definem-se cada vez mais como higienistas. Paralelamente, a higiene mental, que era inicialmente uma aplicação dos conhecimentos psiquiátricos, aparece como a teoria geral que contém e orienta a prática psiquiátrica. [...] A eugenia $^{4}$ foi o artefato conceitual que permitiu aos psiquiatras dilatar as fronteiras da Psiquiatria e abranger, desta maneira, o terreno social. (Op. Cit. p. 29).

É exatamente na ideia não de proporcionar a cura da doença, mas de evitar que haja uma proliferação, que a psiquiatria inicia sua atuação efetiva no Brasil. Haverá, nesse sentido, um aumento considerável dos hospitais psiquiátricos na busca de se preservar a parte sadia do corpo social. A questão da eugenia possibilitava não apenas legitimar a exclusão de determinados tipos, como consolidava a dominação de determinado comportamento sobre os demais. Inicialmente, portanto, percebe-se algo mais voltado para o "ser" dos indivíduos nessa perspectiva de higienização.

A preocupação volta-se para as práticas de higiene corporal e mental, neste último caso, o cumprimento do seu papel social. O estado de Goiás, neste contexto da Liga de Higiene Mental, passa por discussões ressuscitadas por Pedro Ludovico Teixeira sobre a transferência da capital.

Esse ideal de uma nova capital para Goiás catalisou discursos acerca de uma modernidade que a psiquiatria auxiliaria a consolidar. Esta assistência viria mediante aplicação de certa eugenia que projetaria um novo homem para esse chamado sertão.

O sertão é compreendido aqui como uma construção narrativa e não apenas um espaço geográfico, é o par opositor do litoral, no sentido da elaboração de uma modernidade, de uma superioridade. Nesse sentido, a psiquiatria auxiliaria na transformação do comportamento dos sertanejos, especificando a normalidade para um ideal de ser moderno. A modernização representava, principalmente, deixar para trás os

\footnotetext{
4 Criada no século XIX por Francis Galton a eugenia é um conjunto de ideias e práticas relativas a um "melhoramento da raça humana" [...]. Essa proposição teve grande sucesso e, mesmo após o seu questionamento como ciência, ainda se manteve por longo tempo como justificativa para práticas discriminatórias e racistas. No Brasil ganhou vulto nas primeiras décadas do século $\mathrm{XX}$, pois seus pressupostos forneciam uma explicação para a situação do país (que seria de um "atraso") e, ao mesmo tempo, indicava o caminho para superação dessa situação. (MACIEL, p. 01).
} 
laços com a ideia de atraso, da cultura do período pós-mineração encontrado na historiografia goiana do período e nos relatos de viajantes como Saint Hilaire.

A modernização almejada tanto pela esfera estadual como pela federal, nesse momento, justifica a construção do hospital psiquiátrico na cidade de Goiânia. Isso ocorre pelos princípios eugênicos presentes na prática médica psiquiátrica que sofre influência da psiquiatria organicista alemã,

\begin{abstract}
os psiquiatras brasileiros abandonarão a ideia de arianização ou de embranquecimento progressivo e vão reter do racismo a ideologia de "pureza racial", peculiar aos países europeus e à América do Norte. A passagem de uma a outra dessas teorias coincide com a evolução do ideal eugênico. À ideologia do embranquecimento racial corresponderia a noção de eugenia como "higiene psíquica individual" e à ideologia de pureza racial corresponderia a noção de eugenia enquanto "higiene social da raça". (Op. Cit. p. 33)
\end{abstract}

Assim, os médicos da Liga se importarão, principalmente, em possibilitar a projeção de uma nova "raça", de um homem brasileiro que estivesse preparado principalmente para o trabalho, apto a tornar-se efetivo contribuinte da riqueza nacional. O homem é visto unicamente como uma matriz biológica.

\title{
II- Psiquiatria: Uso da Loucura
}

A grande questão que se faz agora é: O que seria/é a doença mental? O comportamento desconexo - isso implica gestos e até mesmo o olhar - serve como caracterização de um sintoma, mas o que faz a doença? De que forma cada cultura se vê mentalmente saudável a partir da doença mental?

O estado de Goiás, na terceira década do século XX, também sofre os impactos da revolução de 1930, que implica novos governantes e uma mudança na sua estrutura política. Tal modificação se dá de maneira abrupta no sentido dos discursos sobre a situação da população. Nesse momento, Pedro Ludovico Teixeira ${ }^{5}$ surge como uma personagem dessa transformação política e cultural.

Sua formação permitiu que seu discurso acerca da antiga capital e sobre Goiás fosse validado com mais firmeza. Enquanto médico, procurou descrever a situação de

\footnotetext{
${ }^{5} \mathrm{O}$ mesmo, interventor do governo revolucionário é pai de Mauro Borges já citado nas páginas anteriores deste trabalho.
} 
maneira a exaltar os problemas de higiene e saúde que atingiam a população goiana. Dessa forma, conseguiu subsídios para realizar suas estratégias políticas, como a construção de uma nova capital. Nesse sentido, intensificava a ideia de que o estado estava em uma total precariedade e que a população deveria ser curada, higienizada, para que Goiás pudesse alcançar um patamar superior, o patamar da modernidade. Portanto, que se realizasse uma profilaxia desses males.

Esses discursos visavam construir um homem apto ao trabalho, já que o mesmo era visto como algo intrínseco ao homem saudável, não estar apto a realizar tais tarefas colocava o indivíduo em situação de anormalidade. Esse ideal é disseminado a partir do discurso de que seria através de uma população saudável que se poderia alcançar um melhoramento econômico. Por consequência, deixar o estágio de precariedade em que o estado se encontrava.

Essas conjecturas permearam o período anterior à construção da nova capital, como estavam presentes também após a sua construção. Em ofício da Liga Goiana de Obras Sociais encaminhado ao Secretário do Interior e Justiça de Goiânia, Dr. Camargo Júnior, pede-se que um funcionário encaminhe algum parente doente, ou que se faça a busca em mendigos e pedintes para realização de uma experiência terapêutica em Caldas Novas, assim justificada:

Trata-se de uma campanha não apenas humana, mas de sentido patriótico. Fazendo voltar ao trabalho um doente completamente são, presta-se serviço a este País, que o recupera para seu progresso, e, curando as dores de um ser humano, que sem esse auxílio não teria meios para tratar-se, realiza-se obra de perfeita caridade e amor à humanidade. (ARQUIVO PÚBLICO ESTADUAL)

O progresso só poderia se tornar real a partir de um desenvolvimento econômico, de um aumento da produção. Goiás, nesse sentido, deveria tornar tanto o homem do campo mais disposto ao trabalho, como também preparar para o processo de industrialização das cidades. Dessa forma, a população deveria estar preparada para este novo período, as transformações deveriam ocorrer no sentido de projetar um novo homem que estivesse sempre apto ao trabalho, encarando-o como um dever social.

A classe médica goiana, já na década de 1950, passou a defender a sua faculdade de medicina, buscando apoio em outras localidades. Durante o $1^{\mathrm{o}}$ Congresso da 
Associação Médica Brasileira, realizado em Ribeirão Preto, no ano de 1956, esteve presente o representante da Associação Médica de Goiás, Dr. Francisco Ludovico de Almeida, que pronunciou algumas palavras:

\begin{abstract}
A carência de luz elétrica, de água canalizada e de ambiente hospitalar e mesmo a falta de uma vida social mais intensa, são condições que amedrontam os moços acostumados ao asfalto. Por outro lado, também a ideia de isolamento e da rotina faz, com justa razão, que o recém-saído da Escola, cheio de planos para o futuro, não se sinta encorajado para enfrentar regiões tão inóspitas.[...] obrigatoriedade a todos os alunos que se formarem por essa Faculdade de trabalhar um ano em localidades do interior do Estado, onde não exista profissional de medicina radicado. (Revista Goiana de Medicina, jan./fev. 1959, grifo теи)
\end{abstract}

A faculdade de medicina era apenas um plano, mas se expressa nessa fala a preocupação com o homem do campo. Goiânia não se torna apenas um local privilegiado, a representação da saúde do estado, mas se distancia do isolamento. O isolamento aqui colocado não é o trabalhado por Luís Palacin, de Goiás em relação a outras localidades, mas falo do interior em relação à capital. O que se levanta dessa narrativa composta pelo representante da Associação Médica é a composição de um sertão dentro de outro sertão, uma sobreposição discursiva com base na construção de uma identidade saudável para a nova capital.

O que chamo de sobreposição discursiva atua na possibilidade de emergir, de um mesmo local, representações diferentes, que tratam de um processo de autoafirmação, como é o caso de Goiânia. A capital se torna o espelho do estado, é necessário que a mesma seja vista como diferente do ruralismo em que ainda se encontrava Goiás. Se o homem da cidade fosse curado, o sertão moderno já estava existente, porém, ainda se encontrava delimitado por fronteiras sanitárias, no caso da zona rural. Têm-se aí a construção de um sertão dentro do sertão; o que não diminui a importância de estabelecer a cura do sertanejo, de torná-lo apto para o trabalho físico e mental.

A institucionalização da loucura, a produção efetiva da categoria louco terá início a partir do governo revolucionário e o intento de transferência da capital do estado. É neste momento que se configura o ideal de comportamento que servirá a interesses políticos e que a psiquiatria auxiliará, devido ao seu grande poder de intervenção social. 
Isso nos faz retornar à autora já citada, Ana Bock, que afirma que toda cultura cria suas zonas patológicas. O discurso realizado pelo Estado nesse momento é de que Goiás se vê enquanto o sertão que dizem sobre ele. Enxerga-se enquanto um dos berços da nacionalidade brasileira e que, portanto, é necessário realizar cura e profilaxia, isso conduz também a ideia de progresso alcançada pelo trabalho.

É nesse contexto que será cunhada a primeira definição de louco em Goiás. Diante desse quadro em que o Estado detém o poder da narrativa, consegue construir juntamente ao saber médico as fronteiras necessárias entre normalidade e anormalidade, de acordo com os interesses políticos do momento. Os tidos como vadios, alcoólatras e agitadores, que possuíam vícios que poderiam conduzir a sociedade ao fracasso na visão do discurso vigente na época, configuravam os anormais.

Em um dos discursos de inauguração do Hospital Psiquiátrico Prof. Adauto Botelho, em Goiânia, em 1954, o então presidente da instituição Dr. Geraldo Brasil disse as seguintes palavras endereçadas ao Ministro da Saúde que se encontrava presente na solenidade:

Foi para nós, do coração do Brasil, nós que marchamos para o Oeste num verdadeiro sentido de brasilidade, motivo de grande júbilo a criação do Ministério da Saúde. [...] Como é do vosso conhecimento, vosso idolatrado Pai, pioneiro da emancipação do serviço de saúde no Brasil, afirmara em 1930, que: "Não havia ainda penetrado em todas as consciências, que a primeira riqueza de uma nação, é o homem, o seu sangue, o seu cérebro e seus músculos e que ela estaria fatalmente condenada à decadência, quaisquer que fossem os tesouros que encerrassem quando o homem que os habitasse nos os merecesse.” [...] (ARQUIVOS DE SAÚDE PÚBLICA).

Mais adiante, se refere ao médico Adauto Junqueira Botelho, que também estava presente na solenidade:

Para atender às exigências das modernas correntes psicodinâmicas, o serviço de Higiene Mental tão sobranceiramente por vós impulsionado é por demais justificado e coaduna-se perfeitamente com o presente e o futuro da psiquiatria. Hoje mesmo tivestes oportunidade de encarecer o valor desta medida profilática, ao afirmar que o aumento das psicopatias acompanha o avanço da civilização. Esta assertiva aparentemente paradoxal está coerente com o que observamos. (Folha de Goiás, 03/04/1954, grifo meu) 
Neste documento, podemos perceber a contextualização que se constrói, possibilitando a constituição de uma identidade para o louco neste período. Tais ideais dos discursos emitidos durante o governo revolucionário de 1930 parecem se consolidar nas ações realizadas na década de 1950.

Pode-se observar no último trecho do documento que, de fato, os psiquiatras se sentem higienistas, a intenção não é curar, mas realizar uma profilaxia. O Dr. Geraldo Brasil recorre à representação da Marcha para Oeste que visava à busca por uma nacionalidade que seria autêntica. No caso goiano, essa brasilidade parece ter sido encontrada quando o mesmo assume tal identidade como representante da nação.

Outro trecho que nos traz à contextualização é: "A primeira riqueza da nação é o homem". Ao citar o pai do Ministro da Saúde refere-se à importância do trabalho, porque é exatamente dos braços, ombros e sangue deste homem que se pode produzir a verdadeira riqueza da nação. Tal documento não escapa à própria produção narrativa, o retorno ao passado para realização da busca de sentido para o que naquele momento era o presente, dessa forma,

a narrativa histórica se trata afinal de contas da identidade daqueles que têm de produzir esse sentido da narrativa (histórica), a fim de poderem orientar-se no tempo. [...] A narrativa histórica é um meio de constituição da identidade humana (RUSEN, 2001, p. 64).

Esse resgate das viagens civilizatórias no documento assume a identidade sertaneja, colocando-se como produto do imaginário de 1930. Também traz as justificativas necessárias para a atuação do governo no sentido de buscar uma cura e profilaxia para o sertão.

A Liga Brasileira de Higiene Mental, a partir do governo revolucionário, passa a ser substituída pelo Serviço Nacional de Doenças Mentais (SNDM). Este

\footnotetext{
foi criado durante a ditadura getulista e foi montado e organizado por Adauto Botelho. O sucessor do SNDM é a atual Coordenadoria de Saúde Mental do Ministério da Saúde. Adauto Botelho, em 1940 assumiu a direção da Divisão de Assistência a Psicopatas do Distrito Federal e por sua iniciativa foi criado em 1941 o Serviço Nacional de Doenças Mentais (SNDM).

Decreto 17185 de 18 de novembro de 1944 aprovou o regimento do SNDM destacando entre suas finalidades:

1. Superintender as atividades dos órgãos oficiais de assistência a psicopatas existentes no Distrito Federal;
} 
2. Planejar para o território nacional os serviços de assistência e proteção aos psicopatas, coordenando e fiscalizando as respectivas instalações e atividades.

3. Opinar sobre a organização de qualquer serviço público ou particular de assistência e proteção a psicopatas, rever códigos, regulamentos e regimentos que cuide do assunto;

4. Manter organizado o cadastro de estabelecimentos oficiais e particulares de assistência e proteção a psicopatas, atualizando as respectivas atividades.

5. Incentivar o desenvolvimento das atividades que visem a saúde mental, inclusive, dentro dos serviços estaduais de saúde pública;

6. Realizar estudos e investigar a respeito de etiopatogenia, profilaxia e tratamento das doenças mentais;

7. Facilitar o ensino da Psiquiatria em suas dependências.

Vai ser de acordo com o SNDM que haverá expansão dos hospitais psiquiátricos pelo Brasil, sob direção do médico psiquiatra Adauto Junqueira Botelho. Serão construídos oito hospitais destinados aos alienados, sendo um desses o de Goiânia, inaugurado no último ano de seu mandato, em 1954.

Vale ressaltar, ainda, que este é um dos primeiros a serem entregues para a população. Sobre as suas determinações, há de se perceber a perspectiva de profilaxia e não de cura, um serviço centralizado, visto que todo auxílio aos doentes mentais será subordinado a esse órgão que realiza essa grande proliferação dos hospitais.

Às dezessete horas do dia quatro de abril do ano de $1954^{6}$ tinha início, no setor Nova Vila, a cerimônia de inauguração do Hospital Psiquiátrico Prof. Adauto Botelho. Esse nosocômio foi entregue à sociedade em grande estilo, estando presentes o próprio Adauto Junqueira Botelho, o Ministro da Saúde Miguel Couto Filho, o governador Pedro Ludovico Teixeira, entre outras personalidades.

Em uma espécie de agradecimento a Deus por sua existência, ou autorização do mesmo para funcionamento, o Pe. Luiz de Matos efetuou a bênção do nosocômio. Isso nos remonta a tempos anteriores, quando a Igreja Católica era responsável pela manutenção dessas instituições. É claro que nesse momento a sua influência não será tão grande como antes, contudo, a sua presença ainda se faz de forma marcante, como se não houvesse uma confiança, uma certeza de um bem-estar para a instituição caso não realizasse a cena da bênção.

\footnotetext{
${ }^{6}$ Informações extraídas do Jornal $O$ Popular arquivado na Secretaria de Saúde do Estado de Goiás datado do dia 04/04/1954.
} 
A grande influência da igreja nos manicômios é exemplificada por Foucault em seu livro História da Loucura, em que discute a presença marcante da Igreja Católica quando os leprosários começaram a ser povoados pelos loucos. Esses locais passam a funcionar como uma espécie de caminho para o céu, para a redenção dos pecados, tanto de quem lá estava internado como para quem lá trabalhava. Apesar de não mais no controle dessas instituições, no sentido da libertação, a Igreja Católica mantém-se presente, apesar de práticas menos intervencionistas.

Assim, é feita a inauguração do nosocômio. Nessa perspectiva de caridade, o Secretário de Saúde, José Peixoto da Silveira, pronuncia em seu discurso:

\begin{abstract}
E ao ensejo da inauguração do Hospital Prof. Adauto Botelho, eu me felicito, e a todos vós, pela oportunidade que se nos depara, pelo motivo que aqui nos congrega, fazendo-nos vibrar no mais puro e santo entusiasmo, em que nos despersonalizamos, para nos integrar na grande epopeia do amor aos nossos semelhantes.

Este nosocômio nasceu por força do convênio assinado no início de 1947, entre o S.N.D.M., pelo seu Diretor Prof. Adauto Botelho e o Estado de Goiás, pelo Senador Dário Cardoso, como representante desta Unidade da Federação, tendo sido as obras contratadas com a Firma Goianenge, que a iniciou em 1948. (Folha de Goiás, 03/04/1954).
\end{abstract}

Vistos apenas como um grupo de desassistidos, a construção do sanatório tem vistas a auxiliar os necessitados. Nesse sentido, parece que a intenção não é apenas de confinar os inadaptados, porém, não é a realidade mostrada pela atuação do hospital nos anos em que esteve funcionando. Ao delimitar o louco neste primeiro período que se inicia no ano de 1954, a preocupação foi a de auxiliar nesse processo de limpeza social, evitando que a degenerescência fosse transmitida a gerações posteriores. Aqui já nos cabe concluir depois de toda a contextualização a intenção que se tinha em relação ao homem sertanejo, e, no caso específico, ao goiano. No mesmo documento acima citado, o Secretário de Saúde ainda expõe:

Dentre os deveres primordiais do Governo nenhum pode sobrepor-se ao de assistir à saúde do povo; este problema no nosso vasto Brasil encerra tamanha gravidade, tal amplidão e magnitude, que para ele se deve atentar com grande patriotismo; os recursos e os esforços máximos do Governo precisam ser mobilizados para curar, robustecer e valorizar o homem brasileiro.

Sintetiza-se nestas palavras, o zelo de um homem pela vida de nossa gente, e definem-se os propósitos do Governo de promover o aperfeiçoamento da nossa raça. 
Política e medicina estão aqui colocadas de mãos dadas na tarefa benéfica de projetar um novo homem para a representação da nacionalidade. O Estado é tido como veículo condutor, porque possui a possibilidade de colocar o controle exercido pela medicina, e aqui, no caso a psiquiatria, em prática. Esse enlace proporciona a legitimação dos discursos excludentes tanto por parte do governo como por parte dos médicos. O próprio ideal eugênico estava presente em ambos os discursos que necessitavam um do outro para realização das práticas que acreditavam poder trazer ao Brasil e a Goiás uma nova face.

Seria algo como a metáfora de um corpo, um organismo vivo em que o dever do Estado é a proteção de seu povo. Tal política é colocada em prática por Vargas e seguida pelos seus representantes nas federações, que auxiliam na composição de um governo que é visto como a cabeça, parte responsável pela percepção daquilo que faz mal ao seu componente físico.

Contribuição maior sobre essa metáfora da nação enquanto corpo nos dá Alcir Lenharo, em sua obra Sacralização da Política, em que elucida a forma como o Estado se atribui tal imagem, quando se "apresenta como o único sujeito histórico adequado ao país para aquele momento (1937) e, ao mesmo tempo corretor da sua linha de evolução histórica" (LENHARO, 1989, p. 13).

Torna-se, então, função do governante elaborar políticas que visem à saúde dos seus, retirando de sua corrente circulatória os 'vírus' que poderiam adoecer-lhe, tornando o corpo frágil, passível de mais infecções que o fariam sucumbir. Dessa forma, ao se referir à 'purificação de nossa raça', entende-se a exclusão daqueles que poderiam atribuir fragilidade genética ou ao ambiente das gerações futuras, comprometendo a pretensa modernidade que se tinha como expectativa.

A própria caridade discutida em documento anterior não é simplesmente aquela aprendida nos bancos das igrejas, ela deixa de ser algo apenas divino e, no caso individual, para ser a salvação de uma nação inteira, sendo representada como um dever patriótico.

Nos primeiros anos de atuação do Hospital Psiquiátrico Adauto Botelho (1954), o mesmo age como legitimador dos discursos acerca da raça, da eugenia e da exclusão dos não adaptados. Incluídos nestes estão os ditos vadios, que tinham artigo previsto em 
lei autorizando sua prisão, sendo que muitos eram levados à internação. Encontra-se em relatório de ano de 1964 do S.N.D.M., considerada como causa Exotóxica da loucura questões relacionadas à profissão.

O louco em Goiás já estava identificado, sua identidade estava construída e seu lugar estava definido. Se, antes da construção do manicômio, havia uma relação entre a população e aqueles que, sofrendo de algum distúrbio da norma, encontravam-se ainda presentes no corpo social, mesmo que como um errante pelas ruas, agora não mais. Há um local para ele, seu nome ou apelido é substituído pela categoria de 'doente mental', que, no final da década de 1950, mostra-se definida, como se pode observar no artigo de Alfredo Paes ${ }^{7}$ publicado na 'Revista Goiana de Medicina' do ano de 1959 intitulado de 'Insanos Morais': "Personalidade normal, é aquela: livre de sintomas, desembaraçada de conflitos, dotada de satisfatória capacidade de trabalho, apto para amar o próximo como a si mesmo".

Essa definição, essa nomeação que se tem no presente artigo nos traz agora dentro da psiquiatria a preocupação de tornar o homem apto para o trabalho. Este, visto como algo não apenas necessário à sobrevivência individual dado ao modo de produção vigente, mas como um dever patriótico de cada componente social. Ainda neste meio, certa dose de religiosidade, uma presença cristã, mas que não define as palavras, não define amor. Mais adiante, realizando uma classificação, uma relação das causas de insanidade ele acrescenta:

b) Educação defeituosa:

A) Disarmônicos: sobrexcitáveis-explosivos, Instáveis-faltos de perseveração, débeis de vontade, Instintivos ou vagabundos-tendência às toxicomanias em geral, Fraudadores e mentirosos-pseudologia fantástica, Insociáveis ou anti-sociais - ausentes de sentimentos éticos 'loucos morais', Pseudopleitistas - discutidores (discutem por esporte).

B) Paredônicos: São os que apresentam perversões da função sexual traduzidas no impulso genético; sadismo, fetichismo, exibicionismo (exposição dos próprios órgãos genitais e masturbação em público), ninfomania, satiríase, homossexualismo, necrofilia (coabitação com cadáveres), bestialidade (congresso com animais)."

Um pouco mais adiante finaliza:

\footnotetext{
${ }^{7}$ Durante o ano de 1959, atuou como Neuropsiquiatra do Hospital Psiquiátrico Prof. Adauto Botelho Goiânia, Goiás.
} 
Um indivíduo portador de insanidade moral apresenta desordem na esfera do sentimento, temperamento ou hábito, com as funções intelectuais quase que íntegras. É a 'Moral Insanity' de Prichard e vive por meio de uma norma de moralidade de pensamento subjetiva determinada por seu próprio prazer ou por artifícios. Não reconhece que existe um padrão objetivo para o certo e o errado, permanente e independente do seu ponto de vista. (Revista Goiana de Medicina, jul./set. 1959).

A caracterização da personalidade tida como normal por Alfredo Paes estrutura o indivíduo que seja normal como estando livre dos conflitos. Pressupõe e atua de forma a incluir dentro de uma categoria de exclusão social outros grupos sociais que estejam fora da heteronormatividade cristã e alienada para o mundo do trabalho.

O autor ainda especifica claramente a categorização dos que ele chama de 'vagabundos-tendência', dos que discutem por esporte. Aqui estão encerrados aqueles que não se enxergam enquanto membros responsáveis pela edificação do estado e do país através do trabalho, e os que contestam as normas estabelecidas. O autor deixa claro que os 'Insanos Morais' possuem uma moralidade subjetiva criada por eles mesmos, não reconhecendo um padrão de certo e errado estabelecido pelo Estado.

Aqui o que está sendo julgado e interditado é a consciência do indivíduo, o impedimento de pensar e agir fora dos padrões que determinam as diferenças entre certo e errado, verdade e mentira, em que o comportamento social é pautado. Assim, as zonas de exclusão em torno do considerado normal e do anormal são traçadas a partir desses discursos que constroem essas identidades, que têm como emitente o Hospital Psiquiátrico. Este se torna símbolo dessa exclusão considerada limpeza, onde são trancafiados os discursos que poderiam vir a contrapor a norma vigente nos diferentes contextos históricos. No caso de Goiás, percebe-se a preocupação com higienização e sanitarização na década de 1950 até 1960, quando o comportamento passa a ser mais abarcado pela psiquiatria até meados da década de 1970, em que se tem início as denúncias e a luta antimanicomial.

\section{Conclusão}

O Hospital Psiquiátrico Adauto Botelho de Goiânia foi importante no contexto em que o estado de Goiás estava na primeira metade do século XX. A transferência da 
capital, alicerçada no discurso médico, consolidou uma nova perspectiva a partir da intervenção de Pedro Ludovico Teixeira, em 1930.

Naquele momento, o ideal de modernidade era parte importante do discurso político, utilizando-se da medicina como forma de alcance das expectativas. $\mathrm{O}$ homem do sertão deveria ser curado e robustecido, a metáfora caracterizada pelo Jeca Tatu de Monteiro Lobato deveria desaparecer e dar espaço a um novo homem sertanejo.

$\mathrm{Na}$ busca pela modernidade, era necessário transformar o comportamento dessa “civilização do interior”, este espaço considerado de uma cultura genuína que deveria ser reorganizado pela Marcha para o Oeste. Goiânia, a nova capital do estado de Goiás, não representa apenas os anseios da nova conjuntura política que pretendia se afastar das famílias coronelistas, mas condensava os ideais do governo Vargas.

Uma capital projetada no interior para ser moderna representaria a perspectiva do Estado, e, no entanto, trabalhos acadêmicos como de Nasr Chaul e Eliézer Cardoso de Oliveira nos demonstram a existência da tradição e da modernidade nos primeiros anos da cidade. Era importante demarcar o comportamento, deixar para trás traços que relacionassem com o antigo Goiás e, para isso, a psiquiatria se mostrou uma grande aliada.

Se anteriormente, nas pequenas cidades e antiga capital, sabia-se o nome dos chamados loucos e seus apelidos, era preciso que a categorização fosse efetivada para que esta pessoalidade ficasse para trás. Ao mesmo tempo em que funcionava como forma de constituir uma categoria, a construção do sanatório também representaria o comportamento aceito naquela nova sociedade.

Nesse sentido, a construção do manicômio Adauto Botelho foi importante como legitimador do discurso de exclusão daqueles comportamentos não mais desejados, uma forma de conduzir esta sociedade para algo planejado desde o lançamento da pedra fundamental de Goiânia.

\section{Bibliografia}

BOCK, Ana. Indivíduo Sociedade: uma relação importante na psicologia social. In: BOCK, Ana. A Perspectiva Sócio-Histórica na Formação em Psicologia. Petrópolis (RJ): Ed. Vozes, 2003.

COSTA, Jurandir Freire. História da Psiquiatria no Brasil. Rio de Janeiro: Ed. Campus, 1980. 
ENGEL, Magali Gouveia. Um Palácio para Guardar Doidos. Revista de História da Biblioteca Nacional, ano 01, n. 02, ago. 2005.

FREITAS, Lena Castello Branco Ferreira de. Saúde e Doenças em Goiás - A medicina possível. Goiânia: Ed. UFG, 1999.

LENHARO, Alcir. Sacralização da Política. Campinas (SP): Ed. Papirus, 1986.

LIMA, Nísia Trindade Um Sertão chamado Brasil. Rio de Janeiro: Ed. Revan, 1999.

PALACIN, Luiz. Fundação de Goiânia e Desenvolvimento de Goiás. Goiânia: Ed.

Oriente, 1976.

RUSEN, Jorn. Razão Histórica. Brasília: Ed. UNB, 2001.

\section{Fontes:}

ARQUIVO PÚBLICO DE GOIÁS, Goiânia. Revista Oeste, jul. 1942.

ARQUIVO PÚBLICO DE GOIÁS, Goiânia. Jornal Folha de Goiás, abr. 1954.

FACULDADE DE MEDICINA (UFG), Goiânia. Revista Goiana de Medicina, jul./set. 1959.

SECRETARIA ESTADUAL DE SAÚDE, Goiânia. Arquivos de Saúde Pública. set. 1951 a abr. 1954.

\section{Sites Pesquisados:}

http://www.ufrgs.br/bioetica/psiqpes.htm Acessado em: 28/02/2010 23:13.

http://www.scielo.br/scielo.php?script=sci_arttext\&pid=S1516-44462000000400007 Acessado em: 28/02/2010 23:17.

http://www.ufrgs.br/ppghist/anos90/11/11art7.pdf Acessado em: 28/02/2010 23:41. 